\title{
Protestas, pandemia y salud: manera, tiempo y lugar
}

\author{
Domingo Lovera Parmo*
}

The shops are locked, the businesses closed, the courts and the lawyers dragged away, prostrating the laws.

Niccolò Machiavelli, Pistola fatta per la peste lorenzo

a' Girolamo di Maestro luca in Villa**

\begin{abstract}
RESUMEN
En el contexto de la pandemia se han decretado varias medidas restrictivas de las libertades. El derecho a la protesta no ha sido la excepción. En términos generales, los Estados han echado mano al peligro que la transmisión del virus acarrea para la salud, para imponer fuertes restricciones a las reuniones públicas. Este trabajo revisa algunas sentencias del derecho comparado, a efectos de anotar que los tribunales, al evaluar la constitucionalidad de esas medidas, llaman la atención sobre el respeto a los derechos involucrados. La proporcionalidad de las medidas -han sostenido esos tribunales-debe evaluarse incluso en contextos de pandemia. Esto que parece obvio -a final de cuentas, la proporcionalidad suele utilizarse para evaluar medidas que regulan derechos $y$ libertades-, debe destacarse en momentos en que el miedo, como enseña la historia y quizá nuestra propia jurisprudencia reciente, nos lleva a recepcionar estas medidas de forma acrítica.
\end{abstract}

Protestas; Covid-19; restricciones de derechos

Protests, pandemic and bealth: manner, time and place

\begin{abstract}
In the context of the pandemic, States have enacted multiple measures that restrict rights and liberties. The right to protest has not been the exception, with States alluding to the dangers the virus poses to bealth in order to impose heavy restrictions on public gatherings. This article examines a number of judicial decisions from different jurisdictions, to show how courts call on governments to respect affected rights when reviewing the constitutionality of such measures.
\end{abstract}

* Licenciado en Ciencias Jurídicas y Sociales, Universidad Diego Portales, Chile. Magíster en Derecho, Columbia University, Estados Unidos. Doctor en Derecho, York University, Canadá. Profesor de Derecho Constitucional, Universidad Diego Portales, Chile. ORCID: https://orcid.org/0000-0002-3601-096X . Correo electrónico: domingo.lovera@udp.cl

Artículo recibido el 15.9.2020 y aceptado para su publicación el 8.4.2021.

*** Reproducida en LANDON, 2013, p. 179. 
Even in times of pandemic, the article shows courts find that the proportionality of regulations may be judicially assessed. Although this line of reasoning may appear obvious -it is a standard globally resorted to review rights limitations-, it needs to be highlighted in times when fear, as history and our own recent jurisprudence show us, may lead to uncritically accept these restrictions.

Protest; Covid-19; rights restrictions

\section{INTRODUCCIÓN}

$\mathrm{L}$ a expansión mundial del Covid-19 ha trastocado todas las actividades. La mayoría de ellas se han visto restringidas y sometidas a severas regulaciones gubernativas. La obligación de permanecer en casa, el cierre de locales de atención al público y la restricción de acceso a lugares que permitan la reunión simultánea de personas, han sido todas medidas adoptadas con el objetivo de "aplanar la curva". Las protestas, esas reuniones esporádicas que tienen lugar en el espacio público, no han sido la excepción ${ }^{1}$.

Este trabajo se centra en estas últimas por tratarse el derecho de reunión no solo uno más que ha resultado afectado por las regulaciones, sino el que ha sido su objeto de atención principal ${ }^{2}$. Las regulaciones adoptadas en el contexto de la crisis sanitaria, en efecto, se han dirigido especialmente contra las actividades que tiene lugar en el espacio público, que ha terminado severamente constreñido ${ }^{3}$. Mientras las consecuencias a largo plazo de esas restricciones están por verse ${ }^{4}$, acá se propone la revisión exploratoria de las sentencias más relevantes de tribunales de jurisdicciones comparadas adoptadas a propósito de la realización de las protestas. Para efectos de esta exploración, todas las jurisdicciones citadas comparten un mismo tipo de arreglo institucional: mecanismos de control judicial de emergencia habilitados para escrutar el respeto a los derechos fundamentales por parte de las medidas adoptadas para el resguardo de la salud pública. Esto está lejos de ser una novedad en nuestra propia tradición ${ }^{5}$. Este estudio cualitativo preliminar $^{6}$, limitado en su alcance y que necesitará futuro complemento, permitirá iluminar la discusión que se instaló con la pandemia: ¿bastan solo las consideraciones de salud pública a la hora de escrutar las regulaciones a que son sometidos los derechos en situaciones de emergencia sanitaria?

${ }^{1}$ De acuerdo con el art. 43 inc. $3^{\circ}$ del texto constitucional, la declaración del estado de excepción constitucional de catástrofe - decretado en Chile en marzo de 2020-, habilita al Presidente de la República para restringir las libertades de locomoción y de reunión.

2 Bethike y WolfF, 2020, p. 372.

3 Bethke y Wolff, 2020.

${ }^{4}$ Honey-Rosés et al., 2020, p. 4.

5 Así, este trabajo no apunta a trasplantar "ideas constitucionales", sino a observar la forma en que diferentes jurisdicciones han resuelto problemas comunes echando mano a arreglos institucionales similares. Tushnet, 2008, pp. 14-5.

${ }^{6}$ Se trata de una comparación funcional de la revisión judicial de medidas regulatorias de la protesta en contextos de pandemia, en los términos de JACKsON, 2012, pp. 62-5. 
La respuesta a esta pregunta dista de ser obvia ${ }^{7}$. Nuestra experiencia, así como la $\operatorname{comparada}^{8}$, muestra que en general ha existido una falta de atención a cualquier otra consideración diferente a las sanitarias y el uso de poderes de emergencia a la hora de evaluar las medidas de las autoridades 9 . Se ha sugerido que ha sido el caso de nuestras cortes, también. Una pesquisa inicial realizada en el buscador Legal Publishing, utilizando el término "COVID-19" para identificar sentencias entre el 1 de enero y 4 de septiembre de 2020, arrojó 29 acciones de protección presentadas al respecto. De ellas, si se seleccionan solo las intentadas en contra de órganos del Estado y a propósito de las medidas adoptadas en contexto de pandemia, se acogieron 2 y se rechazaron 12 . Es cierto que varias de las acciones rechazadas solicitaban restricciones antes que cuestionar las impuestas. De todas formas, desde un punto de vista sustantivo en todas esas sentencias puede anotarse una actitud particularmente deferente para con las autoridades. En general los tribunales reiteraron que, "no obstante, habiéndose declarado por el Presidente de la República el Estado de Catástrofe en todo el territorio nacional, es manifiesto que el mérito, oportunidad, conveniencia y eficacia de tales medidas queda radicado de manera privativa en las autoridades recurridas, toda vez que responden a la ejecución de una política pública de orden sanitario" (cons. $\left.2^{\circ}\right)^{10}$.

¿A qué puede deberse esta actitud especialmente deferente frente a las restricciones de derechos? La historia nos muestra que estos son escenarios que se han repetido anteriormente $^{11}$. Cómo entonces, la pandemia, fue capaz de generar un escenario de pánico que nos empujó a recibir de forma poco crítica estas restricciones ${ }^{12}$. De paso, los Estados encontraron en ese miedo campo fértil para proceder a establecer intensas regulaciones al ejercicio de derechos (Chile va a enterar un año sujeto a toques de queda nocturnos) ${ }^{13}$, lo que está lejos de ser una moda solo en países con débiles credenciales democráticas ${ }^{14}$.

${ }^{7}$ Para entender esto el contexto es crucial. Solo por poner un ejemplo: mientras en el último tiempo proliferaba la aprobación e implementación de leyes que castigaban incluso penalmente el uso de máscaras en protestas, utilizadas como objeto de resistencia, hoy las regulaciones -con esas leyes aún vigentes-requieren su uso. KwoK, 2021.

${ }^{8}$ En efecto, las regulaciones que han seguido a la pandemia parecen haber conferido escaso peso a los derechos y las libertades constitucionales, relegadas a un segundo plano frente a los beneficios sanitarios. Priel, 2020, pp. 538-41. Algunos autores han señalado que la protección de la salud pública y el respeto de las demás libertades se ha transformado en un verdadero dilema en el contexto de la pandemia. CHIA y Oyeniran, 2020; Kampmark, 2020, pp. 1-2.

${ }^{9}$ Esto, desde luego, dista de ser solo una tendencia nacional. SCHEPpele, 2008, 177.

${ }^{10}$ El ejemplo, casi invariable en varias decisiones, está tomado de Corte Suprema, 3.08.20, rol 628972020 cons. $2^{\circ}$. Un análisis respecto de la particular deferencia de nuestros tribunales, acaso provocada por una estrecha lectura de la disposición del art. 45 inc. $1^{\circ}$ CPR, puede encontrarse en Cordero, 2020.

${ }^{11} \mathrm{Y}$ no con los mejores resultados para el respeto de los derechos. Altshuler, 2020.

${ }^{12}$ Durante una crisis sanitaria se desarrolla una mayor tendencia al conformismo y la obediencia. PARRY et al., 2020, p. 1. Un estudio conducido en plena pandemia mostró que el mayor predictor de conformidad con las regulaciones era el miedo a contraer el virus. HARPER et al., 2020.

${ }^{13}$ Como se ha advertido, las regulaciones se han visto favorecidas por un cierto escenario de excepción que las autoridades, echando mano a un lenguaje de confrontación, han construido. SpADARo, 2020, p. 317.

${ }^{14}$ Bethike y Wolff, 2020, pp. 364-8. 
Esto es lo que advirtió el comité de expertos de Naciones Unidas cuando llamó a los Estados a no dejar de observar un enfoque de respeto a los derechos en la imposición de las medidas ${ }^{15}$. Otro tanto la Comisión Interamericana de Derechos Humanos ${ }^{16}$. ¿Acaso las doctrinas de derecho constitucional que hemos desarrollado a lo largo de los años no se aplican en estas circunstancias? ${ }^{17}$

Para cumplir con lo prometido, este trabajo se inicia (II) con una breve referencia a la relevancia político-constitucional de las protestas. Como se dirá luego, (III) esto se extiende a los momentos de zozobra sanitaria, en los que la ciudadanía sigue cumpliendo un rol crucial al mantener su rol vigilante. Finalmente, se reserva (IV) la última sección para abordar las decisiones judiciales relativas a la realización de protestas y que se han dictado en el contexto de la pandemia y de las regulaciones a las que generalmente es sometida la protesta. Como se ha advertido ya, esto se hace para ilustrar la forma en que algunos tribunales han traído a la mesa otras consideraciones que las de las solas razones sanitarias.

\section{LA RELEVANCIA DEL DERECHO A LA PROTESTA}

Como ha señalado Nadia Urbinati, la democracia representativa es un gobierno de dos soberanas ${ }^{18}$. Una de ellas es la soberana de la voluntad democrática que se expresa por medio de procedimientos formales y regulados ${ }^{19}$. La formación de las leyes es una de las formas en que esa soberana habla. La otra soberana es la de la opinión pública, que concurre a conferir legitimidad a la democracia representativa ${ }^{20}$. La opinión pública, a diferencia de la voluntad democrática, se construye fuera de las instancias formales. Ambas soberanas gobiernan en la democracia representativa, se influyen mutuamente y traban un equilibrio dinámico al que comparecen en una misma posición ${ }^{21}$, aunque sin confundirse ${ }^{22}$.

La protesta es una de las formas con las que la ciudadanía concurre a la formación de la opinión pública. Es una forma de discurso público y de aparición política por medio de la que existencias que de otro modo estarían silenciadas, se instalan en el espacio público para constituirse en actores políticos ${ }^{23}$. El derecho, anotando que las protestas

${ }^{15}$ United Nations - Office of the High Commissioner of Human Rights, 2020.

${ }^{16}$ Comisión Interamericana de Derechos Humanos, 2020.

${ }^{17}$ Wiley y Vladeck, 2020, p. 180; JosePh, 2020, p. 254. Esta misma pregunta se hizo, respondiéndola de forma negativa, la Corte Suprema de Estados Unidos al resolver acerca de restricciones al uso de los templos para el ejercicio de cultos en tiempos de pandemia. Corte Suprema de Estados Unidos, 25.11.20, Roman Catbolic Diocese of Brooklyn, New York v. Andrew M. Cuomo, p. 5.

18 URBINATI, 2014.

19 Urbinati, 2014, p. 22.

${ }^{20}$ Urbinati, 2014, p. 27.

${ }^{21}$ Guinier y Torres, 2014, p. 2749.

22 Schmitt, 2008, pp. 271, 275.

${ }^{23}$ Butler, 2015, pp. 9-11. 
son una forma de discurso público por medio de las que la ciudadanía alienta algunas veces y coteja otras las decisiones institucionales, brinda protección constitucional a estas formas de aparición. Así, la libertad de expresión ${ }^{24}$ y el derecho de reunión ${ }^{25}$ suelen concurrir a configurar un derecho positivo a la protesta ${ }^{26}$. Diversos tribunales así lo han reconocido.

Por ejemplo, la Corte Federal alemana señaló en el caso Brokdorf que "el derecho de los ciudadanos a participar en la formación de la voluntad política no solo se expresa votando en las elecciones, sino también ejerciendo influencia en el proceso continuo de formación de la opinión política, la que en un Estado democrático debe ser libre, abierta, sin regulaciones y en principio ajena a la intervención estatal ${ }^{27}$. La Corte Suprema de Chile, por su parte, sostuvo que la protesta "puede ser relevante para generar debates en la opinión pública" ${ }^{28}$. En Canadá, la Corte Suprema ha argumentado que las protestas se basan en un conjunto de derechos fundamentales que representan valores básicos de una democracia ${ }^{29}$. A fines de 2018, la Corte Constitucional de Sudáfrica advirtió que la protesta es esencial en democracias como la nuestra (y la nuestra), en la medida que confiere voz a la sociedad civil para "influir en el proceso político..." ${ }^{30}$. También en 2018, la Corte Constitucional colombiana afirmó que "la reunión y la manifestación pública y pacífica son derechos fundamentales [que] fortalece[n] el principio democrático en el sistema constitucional actual" 31 .

¿Qué es lo que indican todas estas sentencias? Que las protestas contribuyen a la legitimidad de las decisiones políticas al abrir la política a la participación ciudadana más allá del momento autoritativo del voto ${ }^{32}$, colaborando a la realización del ideal del autogobierno. Como lo enfatizara la Corte Constitucional de Sudáfrica, "[1]a democracia participativa es de especial importancia para aquellos sectores de la comunidad que se encuentran relativamente desempoderados en un país como el nuestro, donde existe una gran disparidad de riqueza e influencia" ${ }^{33}$.

La protesta no solo contribuye al ideal de realización del autogobierno en general, sino que para ciertos grupos sociales es la forma que les permite tener voz. Así ha razonado la Corte Constitucional de Colombia: las protestas "contribuye[n] a disminuir el déficit de representación de muchos sectores de la sociedad colombiana y busca 'llamar

${ }^{24}$ Véase, por todos, BAREndt, 2007, pp. 268 y ss. Para el caso chileno Lovera, 2015, pp. 99-119.
${ }^{25}$ Por todas, SAlát, 2015. Para el caso chileno, Lovera, 2020.
${ }^{26}$ Una excepción reciente la representa el Tribunal Constitucional del Perú, que lo reconoció como un derecho autónomo e implícito. Tribunal Constitucional de Perú, 3.07.2020, expediente 00009-2018-PI/TC.

${ }^{27}$ He tomado la traducción de SchwaBe, 2003, p. 195.

${ }^{28}$ Corte Suprema, 4.11.2014, rol 23.540-2014, cons. $6^{\circ}$.

${ }^{29}$ Corte Suprema de Canadá, 24.01.2002, R.W.D.S.U., Local 558 v. Pepsi-Cola Canada Beverages (West) Ltd., pár. 32.

${ }^{30}$ Corte Constitucional de Sudáfrica, 19.11.2018, Mlungwana and Others $v S$ and Another, pár. 63.

${ }^{31}$ Corte Constitucional de Colombia, 7.03.2018, sentencia C-009/18, pár. 31.

32 Urbinati, 2011.

33 Corte Constitucional de Sudáfrica, 17.08.2006, Doctors for Life International v Speaker of the National Assembly and Others, pár. 115. 
la atención de las autoridades y de la opinión pública sobre una problemática específica y sobre las necesidades que ciertos sectores, en general minoritarios, para que sean tenidos en cuenta por las autoridades"”34.

En resumen, la razón de fondo por la que estas diferentes cortes, incluida la nacional, protegen las protestas, descansa, en primer término, en el hecho de que se trata de una forma de ejercicio de derechos y libertades fundamentales. Pero no solo se trata de ejercicio de derechos en general, sino que de uno que permite a las personas tomar parte del autogobierno. De allí que su protección resulte crucial; su resguardo permite "salvaguardar el proceso comunicativo por medio del cual la opinión pública se forma, de modo de asegurar la integridad del gran proceso por medio del cual la opinión pública se transforma en voluntad pública, la ley" ${ }^{35}$. Algunas veces la participación en ese proceso comunicativo tomará la forma de discursos y escritos. Otras, la de piquetes, quema de banderas y carnavales ${ }^{36}$.

\section{III. ¿PRotestar DURANTE LA PANDEMia?}

En la primera parte de este trabajo se han expuesto las razones que en general concurren a justificar la protección constitucional de las protestas. ¿Perviven esas razones en un contexto de pandemia como el que atravesamos? Los tribunales cuyas decisiones más abajo se revisan, no han dudado en enfatizar ese crucial papel que las protestas pueden desarrollar en una democracia representativa. Incluso en contextos de crisis sanitaria. Como las protestas son una forma de ejercicio de derechos, entonces las autoridades, por acuciantes que sean las circunstancias, no pueden sin más obviar el carácter democrático fundamental de las mismas.

Así lo sostuvo la Corte Suprema de New South Wales en Australia, la que resolviendo una petición de las autoridades policiales para prohibir una protesta convocada en solidaridad al movimiento Black Lives Matter (BLM), advirtió que ese interés público no puede sencillamente tornarse invisible: "[l]a corte reconoce el fuerte interés público comprometido en cualquier expresión de opinión pública relativa a este asunto [el asesinato y las consecuencias del racismo en la acción policial]”37.

El Consejo de Estado francés sostuvo un razonamiento similar al sostener que "su ejercicio, en particular a través de la libertad de manifestación o de reunión, es una condición de la democracia y una de las garantías del respeto de otros derechos y

\footnotetext{
${ }^{34}$ Corte Constitucional de Colombia, 7.03.2018, Sentencia C-009/18, pár. 33.

35 Post, 2012, p. 14.

36 Post, 2012, p. 15. Defendiendo una configuración no elitista de la libertad de expresión, véase,

${ }^{37}$ Corte Suprema de New South Wales, 3.07.2020, Commissioner of Police v Gray, pár. 60.
} LOVERA, 2010. 
libertades que también constituyen libertades fundamentales en el sentido de ese artículo, como la libertad sindical ${ }^{38}$.

En Alemania, un tribunal administrativo en Berlín razonó que “[d]ebido a la especial importancia de la libertad de reunión garantizada por los derechos fundamentales (...) para el funcionamiento de la democracia, su ejercicio solo puede ser restringido para proteger otros intereses jurídicos de igual valor, observando estrictamente el principio de proporcionalidad" 39 .

Ahora bien, no se trata de resguardar constitucionalmente las protestas porque se refieran a asuntos de índole político a pesar de que se atraviese un período de emergencia sanitaria; sino que especialmente por ello. Una de las razones que aconseja mantener un ánimo especialmente vigilante a pesar del contexto de emergencia, entonces, es el hecho de que las crisis sociales, sanitarias y de otro orden suelen constreñir la disputa democrática y el disenso ${ }^{40}$. Son tiempos, de hecho, en los que en general la crítica se aporrea en favor de una pretendida unidad.

Así lo ha advertido Roberto Gargarella, en una variante de un argumento que podemos remontar al premio Nobel de economía Amartya Sen ${ }^{41}$. "Con el paso del tiempo, aprendimos también que algunos de esos derechos requieren de una protección todavía más especial". Y ello es así, dice Gargarella, "porque los mismos nos permiten 'mantener a salvo todos los demás derechos'. De allí que pueda verse al derecho a criticar a quienes están en el poder como el 'derecho de los derechos'” 42 . En efecto, retomando a Sen, esto parece ser especialmente cierto en tiempos donde suele imponerse sobre cualquier otra variable un reclamo al saber experto (que no afirmo que no exista) y que en términos constitucionales trae de la mano una consiguiente restricción de derechos como si no existiera ninguna otra consideración que realizar ${ }^{43}$.

Nada de lo que acá se ha dicho supone que el derecho a la protesta (o cualquier otro derecho y libertad) deba triunfar sobre cualquier otra consideración. Más bien se trata de enfatizar, en conjunción con las razones expresadas en la primera parte de este trabajo, que las medidas de regulación de derechos y libertades deben ser cotejadas con otros factores. Contrario a lo que un acercamiento descuidado pudiera sugerir, lo que la pandemia ha mostrado, justamente, es no solo cómo ella coloca en riesgo derechos como la protección de la salud y la vida. Sino que, en especial, "cómo los derechos humanos

${ }^{38}$ Consejo de Estado de Francia, 13.06.2020, M. A... Ligue des Droits de l'Homme Confédération Generale du Travail et autres, pár. 10.

39 Tribunal Administrativo de Berlín, 28.08.2020, 1 L 296/20, pár. II.1.

40 PARry et al., 2020, p. 4.

41 Sen se pregunta, “¿Lpłor qué preocuparse de cosas finas como las libertades políticas si hay cosas tan gruesas como las acuciantes necesidades económicas?”. Sen, 2000, p. 184.

42 Gargarella, 2020.

43 SEN, 2013, p. 8. 
son interdependientes mientras al mismo tiempo reflejan intereses contrapuestos que a veces es difícil reconciliar" ${ }^{44}$. Pero cuya fricción no debemos esconder ${ }^{45}$.

Así, la pandemia no solo no ha podido esconder los reclamos políticos y sociales que venían desde antes ${ }^{46}$, más bien ha profundizado el carácter autoritario de algunos gobiernos, exacerbando las desigualdades raciales y hecho más evidente la brecha entre quienes tienen acceso a bienes esenciales, como la salud, y quienes no ${ }^{47}$. Probablemente el caso más evidente lo representan las protestas raciales por el asesinato del ciudadano afroamericano George Floyd ${ }^{48}$. Estas protestas son especialmente importantes porque, a diferencia de los reclamos que llamaban a deponer las movilizaciones para enfrentar “juntos" la pandemia, lo que esas protestas hacían era justamente llamar la atención acerca de cómo incluso el enfrentamiento de la crisis estaba dejando atrás a las mismas personas que ya se venían dejando atrás ${ }^{49}$. Pedirles a esos grupos sociales colocar las protestas entre paréntesis equivale a demandar solidaridad a quienes estaban siendo más severamente afectados ${ }^{50}$.

En Portugal, por ejemplo, puede mencionarse el conflicto social por el acceso a la vivienda. El reclamo que se había trabado a partir de la formación de coaliciones sociales que reclamaban por el derecho de acceso a la vivienda en medio de la apertura comercial del país para atraer el turismo se mantuvo y agudizó durante la pandemia. ¿Dónde realiza uno la cuarentena, pregunta Mendes, si no hay un hogar al que ir? ${ }^{51}$ Otro tanto pudimos ver en Chile con las que podríamos denominar protestas del hambre. ¿Qué motivó la toma de las calles? La falta de previsión y la tardía reacción en la adopción de medidas capaces de paliar las necesidades económicas. La nueva normalidad de las restricciones sanitarias se encontraba, así, con la "vieja precariedad" 52 .

En otras palabras, las medidas adoptadas por la autoridad durante la pandemia, y sus consecuencias, hicieron evidente la solapada precariedad general de nuestros Estados y de paso agudizaron conflictos sociales que se venían desarrollando previamente y que con la pandemia estuvieron lejos de descansar. Frente a estas carencias no importa si el escenario es uno de pandemia. Precisamente porque es uno tal que esos reclamos se vuelven más acuciantes que antes y reclaman el recurso al repertorio de acciones que, como la

44 Spadaro, 2020, p. 318.

${ }^{45}$ Con notable claridad, de hecho, se ha mostrado cómo parte de los problemas que ha evidenciado la pandemia dicen relación no solo con la sobrerregulación a la que se ha echado mano y que ha afectado derechos y libertades. Sino que, lo que solo hace compleja las cosas, cómo también parte de los reclamos que la interdependencia de los derechos exhibe apunta al poco alcance de las medidas ejecutivas. PozEn y SCHEPPELE, 2020.

46 Aunque nuevos repertorios se han desarrollado. Ismangil y Lee, 2020; Della Porta, 2020.

${ }^{47}$ Kowalewski, 2020, p. 1.

${ }^{48}$ Como veremos más abajo, varias de las sentencias que se revisarán responden a protestas en solidaridad con el movimiento Black Lives Matter.

49 GiBson et al., 2020.

${ }^{50}$ Douglas, 2020, pp. 206-7.

51 Mendes, 2020.

52 Giminiani et al., 2020, pp. 3-4. 
protesta, permiten visibilizar las demandas frente a las autoridades ${ }^{53}$. Las protestas, en este caso, desmontan la creencia de que las medidas tendrían un impacto simétrico en todas las personas ${ }^{54}$. Para retomar las palabras de Douglas, para esos grupos las protestas, no obstante el contexto, "no era una cuestión de elección, sino una necesidad -una cuestión de vida o muerte-" 55 .

Mientras la evidencia indica que las medidas de restricción de movilidad han sido y son una herramienta útil en el control de la expansión de las enfermedades, las medidas mismas han sido siempre controvertidas y han estado acompañadas de sospecha, debates éticos, jurídicos y políticos. De allí que las cuarentenas y otras medidas de restricción de movilidad demanden, precisamente por su naturaleza intrusiva, "atención vigilante para evitar prejuicios e intolerancia" ${ }^{56}$. La confianza pública, finalmente, así como el orden público ${ }^{57}$, deben obtenerse sobre la base de procedimientos informados "regulares, transparentes y con una comunicación comprehensiva que pueda balancear los riesgos y los beneficios de las intervenciones de las autoridades sanitarias" 58 .

\section{LA EVALUACiÓN JUDiCIAL DE LA REgULACióN DE LA PROTESTA EN PANDEMIA}

El derecho a la protesta, como cualquier otro, está sujeto a regulaciones ${ }^{59}$. En su caso particular, esas regulaciones, ya sea que se dispongan en las mismas disposiciones constitucionales que reconocen el derecho de reunión, ya sea que vengan impuestas por otras consideraciones, llevan el nombre de restricciones de manera, tiempo y lugar (MTL). Las regulaciones de tiempo establecen limitaciones a la hora y días en que pueden desarrollarse las protestas ${ }^{60}$. Las regulaciones de lugar, probablemente porque como "un escenario teatral, los lugares llevan o están llenos de significado", establecen limitaciones relativas a los espacios en que es posible protestar ${ }^{61}$. Las regulaciones de manera, finalmente, se refieren a la forma en que deben desarrollarse las protestas, más allá del deber de ser pacíficas. Como añade Salát, se trata de regulaciones relativas al uso de símbolos en espacios públicos, al ruido y otras formas de disrupción que pueden generar las reuniones en los espacios públicos ${ }^{62}$. La literatura especializada las ha recibido de manera ambivalente. Una parte las celebra en la medida que ellas le indican al Estado

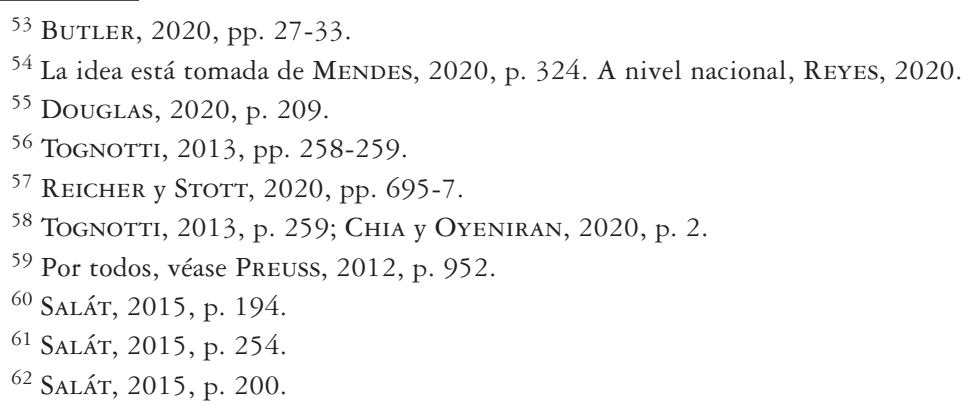


que las protestas no deben reprimirse, sino regularse invitando a sus protagonistas a participar de su establecimiento ${ }^{63}$. Además, se trataría de regulaciones que prescinden del contenido de los mensajes que desean promover sus organizadores ${ }^{64}$. Otra, en cambio, las critica, en la medida que ellas han venido a significar en la práctica la domesticación de las (otrora disruptivas) apariciones públicas ${ }^{65}$.

¿Puede considerarse la salud pública, en el contexto actual, como un criterio para hacer más estrictas estas regulaciones? ${ }^{66}$. En la práctica, este ha sido un giro necesario en el contexto de la pandemia. Esta última sección muestra la forma en que algunos tribunales del derecho comparado han enfrentado este verdadero dilema ${ }^{67}$.

El marco inicial lo ofrece con especial claridad una sentencia del Consejo de Estado francés, que al resolver demandas judiciales que reclamaban contra la estrictez de las medidas, advirtió que:

[e]n el actual período de estado de emergencia sanitaria, corresponde a las diversas autoridades competentes adoptar, con miras a salvaguardar la salud de la población, todas las medidas susceptibles de prevenir o limitar los efectos de la epidemia. Esas medidas, que pueden restringir el ejercicio de los derechos y libertades fundamentales, deben ser, en esa medida, necesarias, apropiadas y proporcionadas al objetivo de salvaguardar la salud pública que persiguen ${ }^{68}$.

Por ello, apuntar al contexto sanitario no es suficiente para exponer el dilema constitucional en su completitud. En la misma sentencia el Consejo señala que, dicha legítima preocupación estatal (un "objetivo constitucionalmente válido”, se lee allí) debe cotejarse con la libertad de expresión y comunicación, "una condición de la democracia..." 69.

${ }^{63}$ Este ha sido el caso de la sociología, SCHweingruber, 2000. Y también desde el mundo de los derechos humanos, Instituto Nacional de Derechos Humanos de Chile - ACNUDH, 2014, pp. 38-41, 52-55.

${ }^{64}$ Aunque esto es discutible si quienes recurren a la protesta son los grupos que -como los ejemplos en tiempos de pandemia han confirmado- se encuentran en las condiciones más desesperadas. La inclusión del principio de igualdad debiera tornar más estricto el escrutinio que se hace de estas medidas. LoverA, 2021, pp. 350-2.

65 Mitchell, 2013.

${ }^{66}$ Algunas regulaciones constitucionales incluyen de manera expresa la protección de la salud pública como una causal de regulación del derecho de reunión, como el art. 38 de la constitución uruguaya. Otro tanto ocurre a nivel regional con el art. 15 de la Convención Americana sobre Derechos Humanos e internacional con el art. 21 del Pacto Internacional de Derechos Civiles y Políticos, el art. 11.2 del Convenio Europeo de Derechos Humanos y el art. 11 de la Carta Africana sobre los Derechos Humanos y de los Pueblos (Carta de Banjul). Allí donde no se dispone específicamente que la salud pública puede servir de base para regular las reuniones en lugares públicos, la expresión orden público podría ser (y ha sido, de hecho) utilizada como base para incluir en ella las preocupaciones por el cuidado de la salud.

${ }^{67}$ A diferencia de las colisiones regulares de derechos, quiero enfatizar el especial dilema que el contexto pandémico trae aparejado. Chia y Oyeniran, 2020.

${ }^{68}$ Consejo de Estado de Francia, M. A... Ligue des Droits de l'Homme Confédération Generale du Travail et autres, pár. 8 .

${ }^{69}$ Consejo de Estado de Francia, M. A... Ligue des Droits de l'Homme Confédération Generale du Travail et autres, pár. 10 . 
Si la salud pública y el cuidado de la salud de los y las demás es un criterio constitucionalmente válido -un criterio objetivo, como señala el ente francés-, ¿es esta la única consideración que debe ponerse sobre la mesa? ¿Qué tan intensas son las medidas regulatorias que pueden adoptarse? ¿Pueden, por ejemplo, prohibirse en absoluto? ¿Basta con invocar la salud pública en términos generales?

\section{Las probibiciones absolutas}

La Corte Constitucional Federal alemana ofrece un primer buen punto de partida. Sostuvo que no se respeta el derecho de reunión cuando se lo sujeta a una prohibición absoluta. En su concepto, hay importantes casos que merecen una cuidada consideración para lo que las autoridades poseen relevantes dosis de discrecionalidad que les permiten acomodar diversos intereses ${ }^{70}$. La autoridad había fallado al evitar buscar un adecuado compromiso entre las medidas sanitarias y el derecho de los manifestantes ${ }^{71}$.

Otro tanto puede señalarse a propósito del debate francés. En Francia se aprobaron una serie de medidas legislativas que buscaban enfrentar la emergencia sanitaria. Una de ellas, que revalidaba el estado de emergencia sanitaria ${ }^{72}$, recibió complementación normativa en materia de reuniones públicas mediante un decreto que las prohibía si participaban más de 10 personas simultáneamente ${ }^{73}$.

La medida fue cuestionada ante el Consejo de Estado. Según los recurrentes, la regulación debía suspenderse al no incorporar ninguna excepción a la prohibición de desarrollo de reuniones en espacios públicos. El Consejo accedió a la petición. Para ello, realizó un examen de proporcionalidad de la medida, concluyendo que el régimen de autorización que se había implementado no lo satisfacía. En sus palabras, la prohibición general y absoluta no puede considerarse "una medida necesaria y adecuada y, por tanto, proporcionada al objetivo de preservación de la salud pública que persigue..."74 . Estas mismas razones fueron invocadas más tarde cuando el mismo Consejo dejó sin efecto las medidas. A pesar de que la autoridad introdujo algunas modificaciones respondiendo a la sentencia del 13 de junio, seguía tratándose de una prohibición absoluta según el Consejo. Nada de esto, en todo caso, importa el incumplimiento de las medidas sanitarias que, como diré más adelante, pueden establecerse por medio de las regulaciones generales ${ }^{75}$.

Estos exámenes consideraron dos factores adicionales que deben tomarse en cuenta. Primero, el contexto sanitario cuya determinación descansa en manos de las

${ }^{70}$ Corte Federal Constitucional de Alemania, 17.04.2020, 1 BvQ 37/20.

71 Mateos, 2021, p. 5.

${ }^{72}$ LOI N $N^{\circ} 2020-546$ du 11 mai 2020, prorogeant l'état d'urgence sanitaire et complétant ses dispositions.

${ }^{73}$ Décret $N^{\circ}$ 2020-663 du 31 mai 2020 prescrivant les mesures générales nécessaires pour faire face à l'épidémie de covid-19 dans le cadre de l'état d'urgence sanitaire.

${ }^{74}$ Consejo de Estado de Francia, M. A... Ligue des Droits de l'Homme Confédération Generale du Travail et autres, pár. 17.

${ }^{75}$ Consejo de Estado de Francia, 26.07.2020, Confédération Generale du Travail et autres Association SOS Racisme. 
autoridades sanitarias. No es lo mismo un escenario de alto contagio que uno de medio o bajo contagio. En segundo lugar, la comparación ¿Qué otras actividades similares (a las reuniones públicas) se restringen de la misma forma? La Corte Suprema de Estados Unidos rechazó levantar las medidas de restricción decretadas en California para el desarrollo de los cultos religiosos porque otras actividades seculares estaban sujetas a medidas igual o más estrictas. Además, sostuvo que los lugares tratados con menos restricciones recibían menos afluencia y permitían que las personas estuvieran con mayor distanciamiento ${ }^{76}$. En el caso de las protestas propiamente tales, la Corte Suprema de New South Wales advirtió que debía mirarse "al momento en que una protesta vaya a tomar lugar [si existan] muchas otras actividades que importan la reunión de personas y que han sido permitidas" 77 .

Un camino diferente tomó la Corte del Distrito Este de California, que aceptó la constitucionalidad de las medidas de prohibición absoluta de protestas producto de la pandemia. ${ }^{78}$ Volveré acerca de esto más abajo, pero por ahora basta con señalar que la Corte sostuvo que se trataba de medidas adoptadas en el contexto de tiempos anormales (abnormal circumstances) y que ellas estaban relacionadas con la protección de la salud pública. Junto con insistir en la necesidad de estarse a la decisión de la autoridad sanitaria ${ }^{79}$, indicó que había canales de comunicación alternativos a los que se podía echar mano, como las redes sociales ${ }^{80}$. El Estado "busca suprimir el virus, no las reuniones expresivas"

El Tribunal Superior de Justicia de España también convalidó inicialmente la constitucionalidad de la prohibición absoluta ${ }^{82}$. Sostuvo que el derecho de reunión contempla el orden público como una hipótesis de limitación ${ }^{83}$ y que ella incluía el resguardo de

${ }^{76}$ Corte Suprema de Estados Unidos, 29.05.2020, South Bay United Pentecostal Church, et al. v. Gavin Newsom, Governor of California et al. En un caso posterior, aunque sin entregar razones, volvió a rechazar los reclamos de una iglesia frente a las restricciones. Los votos disidentes, sin embargo, reclamaron la escasa atención que se prestó a los demás espacios habilitados para el uso en condiciones menos estrictas que las que se establecían para las iglesias. Corte Suprema de Estados Unidos, 24.07.2020, Calvary Chapel Dayton Valley v. Steve Sisolak, Governor of Nevada, et al. Finalmente, en noviembre -en un caso citado más arriba- la misma Corte terminaría levantando las restricciones precisamente al comparar las regulaciones más relajadas que recibían otras actividades. Corte Suprema de Estados Unidos, Roman Catbolic Diocese of Brooklyn, New York v. Andrew M. Cuomo, pp. 3-4.

${ }^{77}$ Corte Suprema de New South Wales, Commissioner of Police v Gray, pár. 66.

${ }^{78}$ Corte del Distrito Este de California de Estados Unidos de Norteamérica, 8.05.2020, Givens et al. v. Newsom et al.

${ }^{79}$ Givens et al. v. Newsom et al., p. 10.

${ }^{80}$ Givens et al. v. Newsom et al., p. 16.

${ }^{81}$ Givens et al. v. Newsom et al., p. 17. En sentido similar resolvió un tribunal de New Hampshire mantuvo la vigencia de una orden del gobernador que prohibía los encuentros públicos ("sociales, espirituales y recreacionales", pero no solo estos) de más de 50 personas. Corte Superior de Merrimack, 25.03.2020, Binford et al. v. Governor Sununu.

${ }^{82}$ Inicialmente, pues el estándar cambiaría a la luz del impacto que habría tenido en ella la sentencia del Tribunal Federal alemán arriba reseñada. Velasco, 2020, p. 126-8. En esa sentencia, el tribunal de Aragón descansó en los contornos del estado de alarma decretado para afirmar que no permitía prohibición absoluta. Tribunal Superior de Zaragoza, 30.04.20, Sentencia $N^{\circ} 151 / 2020$, cons. $3^{\circ}$.

${ }^{83}$ También lo entendió así la Corte Suprema de New South Wales, Commissioner of Police v Gray, pár. 55. 
la salud pública para el caso que fuera a ser puesta en "grave riesgo" ${ }^{84}$. El tribunal fue de la opinión de que la prohibición estaba suficientemente justificada en "la situación de emergencia sanitaria y grave crisis de salud pública en que nos encontramos" 85 y que la medida era proporcional. Así, a pesar de que los recurrentes habían ofrecido echar mano a las medidas sanitarias adecuadas de prevención, indicó que era "muy probable" que todas las medidas sugeridas (distancia social, el recurso a guardias privados para mantenerla, uso de mascarillas, etc.) fueran desatendidas ${ }^{86}$. Sobre esto solo ofreció especulaciones sin mirar al caso concreto.

\section{Regulaciones menos intensas: la prevención sanitaria como manera}

Si la prohibición absoluta es al menos cuestionable ${ }^{87}$, ¿puede la preocupación por la salud pública generar regulaciones MTL? Los casos que revisaremos aceptan esa idea, pero piden algo más. Así, la regla general, podría afirmarse, es que las razones para regular las protestas, incluso cuando esas razones son sanitarias, no pueden darse por establecidas. Así lo expone la Corte australiana antes referenciada: "La verdadera pregunta que debemos enfrentar es acaso la amenaza que importa el virus del Covid-19 es de tal envergadura que las preocupaciones relativas a la salubridad pública, en el contexto actual, son más relevantes que el interés público envuelto en la libertad de expresión y el derecho de reunión" ${ }^{88}$. En un sentido similar se expresó el Consejo de Estado francés ${ }^{89}$. En sus palabras:

En el estado actual de emergencia sanitaria, corresponde a las diversas autoridades competentes adoptar, con miras a salvaguardar la salud de la población, todas las medidas susceptibles de prevenir o limitar los efectos de la epidemia. Estas medidas, que pueden limitar el ejercicio de los derechos y libertades fundamentales, deben (...) ser necesarias, apropiadas y proporcionadas al objetivo de salvaguardia de la salud pública que persiguen ${ }^{90}$.

Como un mes antes el mismo Consejo había razonado, no basta con echar mano a las orientaciones de la autoridad sanitaria, sino que deben considerarse de conformidad a cada caso particular y apreciar si acaso existen condiciones que, como la distancia social,

${ }^{84}$ Tribunal Superior de Justicia de Madrid, 30.04.20, Sentencia $N^{\circ}$ 195/2020, cons. $5^{\circ}$.

${ }^{85}$ Tribunal Superior de Justicia de Madrid, 30.04.20, Sentencia $N^{\circ} 195 / 2020$, cons. $5^{\circ}$.

86 Tribunal Superior de Justicia de Madrid, 30.04.20, Sentencia No 195/2020, cons. $5^{\circ}$.

${ }^{87}$ En tiempos regulares la supresión absoluta de protestas debiera ser observada con especial sospecha.

Corte Europea de Derechos Humanos, 7.02.2017, Case of Lashmankin and others v. Russia, pár. 433.

88 Corte Suprema de New South Wales, Commissioner of Police v Gray, pár. 62.

${ }^{89}$ Consejo de Estado de Francia, 26.07.2020, Confédération Generale du Travail et autres Association SOS Racisme, pár. 10 .

${ }^{90}$ Consejo de Estado de Francia, Confédération Generale du Travail et autres Association SOS Racisme, pár. 11. 
pudieran alinearse con las recomendaciones sanitarias ${ }^{91}$. Otro tanto fue el parecer del Tribunal Superior de Zaragoza: el contexto general de crisis sanitaria no puede acarrear prohibiciones al ejercicio del derecho a la protesta y las regulaciones a que se le someta deben analizarse "caso a caso"92.

Dentro de esta variante, finalmente, un tribunal administrativo de Berlín asumió la que es, quizá, la postura más desafiante de las autoridades estatales (sanitarias y administrativas). Resolviendo un reclamo de grupos libertarios alemanes que solicitaban manifestarse contra de las medidas adoptadas por la autoridad -y que ya habían desobedecido algunas de las mismas precauciones- sostuvo que el reclamo crítico se encontraba especialmente protegido por libertades fundamentales. En lo concerniente a las medidas que apuntan a evitar la propagación de virus, sostuvo que debían evaluarse caso a caso y que era de cargo de la autoridad demostrar que una actividad como la propuesta constituía una "amenaza inmediata a la seguridad o el orden público"93.

En el otro polo, la Corte del Distrito Este de California abrazó una deferencia casi absoluta para con las autoridades sanitarias. Así, junto con insistir en que las medidas de cuarentena y prohibición de protestas eran medidas que claramente buscaban la protección de la salud ${ }^{94}$, agregó que, "en el contexto de esta crisis de salud pública, el poder judicial debe conceder más deferencia a los esfuerzos informados de los funcionarios por proteger a todos sus ciudadanos, especialmente a los más vulnerables, contra una pandemia tan mortal" 95 .

Como se ve, tratándose de derechos fundamentales la mayoría de los tribunales llama a evaluar los antecedentes con que se cuente, el contexto de evolución de la pandemia y el interés público envuelto. Mientras las autoridades políticas reclamaron rápidamente que las protestas propiciaban la propagación del virus, como aconteció con las protestas del movimiento BLM en Estados Unidos, la evidencia ofrecía antecedentes que debían matizar tan tajantes afirmaciones ${ }^{96}$. ¿Por qué? Porque las protestas tienen lugar en espacios abiertos, las personas que protestan han comenzado ellas mismas a tomar medidas de resguardo de su salud y la de las demás, como el uso de mascarillas y distancia social que el espacio abierto favorece (lo que es importante anotar tratándose de protestas que rechazan el uso de estas medidas) ${ }^{97}$. La evidencia preliminar indica que, si las personas van a salir, las tasas de contagio son más bajas si las personas están moviéndose en vez de quietas (como en un banco, una tienda o la estación de policía) ${ }^{98}$.

\footnotetext{
${ }^{91}$ Consejo de Estado de Francia, M. A... Ligue des Droits de l'Homme Confédération Generale du Travail et autres, pár. 14.

92 Tribunal Superior de Justicia de Zaragoza, Sentenca No $151 / 2020$, cons. $4^{\circ}$.

93 Tribunal Administrativo de Berlín, 1 L 296/20, para. II.1.a).

${ }^{94}$ Corte del Distrito Este de California, Givens et al. v. Newsom et al., p. 9.

${ }^{95}$ Corte del Distrito Este de California, Givens et al. v. Newsom et al., p. 10.

96 Neyman y Dalsey, 2020; Dave et al., 2021.

97 Se ha hablado, así, del deber cívico que han desplegado los grupos de protesta que han respetado estas medidas. Gerbaudo, 2020, p. 67.

98 Tello, 2020; JHA, 2020.
} 
Finalmente, debía considerarse el contexto epidemiológico en la medida que las autoridades han desarrollado diferentes fases para evaluar las condiciones de propagación del virus. Por ejemplo, en Commissioner of Police v Gray la Corte Suprema de New South Wales rechazó la petición de la policía de prohibir las protestas convocadas, entre otras razones, por tratarse de una etapa baja (low) de transmisión. En un caso posterior, en que el riesgo se había elevado a medio (medium), la misma Corte accedió a la solicitud policial -incluso cuando, como lo señala la misma Corte, no existía evidencia que permitiera sostener que en una protesta anterior se habían producido contagios-99. El Consejo de Estado francés cuando decidió suspender las medidas de prohibición de protestas, advirtió, descansando específicamente en la autoridad sanitaria, que, "los indicadores epidemiológicos recogidos por la Santé Publique France el 5 de junio de 2020 se encuentran en un nivel bajo en todo el país y no indican una reanudación de la epidemia" ${ }^{100}$. Si el contexto epidemiológico cambia, entonces, podría ${ }^{101}$ llevar al órgano a adoptar una posición diferente $e^{102}$.

Que las personas que recurren a la protesta hayan podido desarrollar prácticas de protección personal y de los y las demás, es relevante por dos consideraciones adicionales. Primero, porque permite en cierta medida atenuar el carácter impositivo de las regulaciones MTL por parte de las autoridades, al tratarse de prácticas de resguardo que las propias personas han desarrollado. Es decir, frente a la tosquedad de la respuesta de la autoridad, la preparación adecuada de las personas puede contribuir a balancear de manera ajustada los intereses en juego. La Corte Federal Constitucional alemana, por ejemplo, sostuvo que se mostraba una baja consideración al derecho de reunión y la libertad de expresión cuando se establecían prohibiciones generales sin prestar atención a las medidas que las mismas personas ofrecían al notificar una reunión ${ }^{103}$. La Corte Suprema de New South Wales, por su parte, tuvo en cuenta esta preparación para rechazar una solicitud de prohibición de una protesta presentada por la autoridad policial ${ }^{104}$.

Nada de esto obsta, por cierto, a que las autoridades ofrezcan protocolos de asistencia a las protestas. En efecto, una protesta "anti-Covid" fue disuelta en Alemania justamente porque sus promotores desafiaron precisamente la adopción de medidas de prevención como el uso de mascarillas y distanciamiento social. No obstante habían acordado el

${ }^{99}$ Corte Suprema de New South Wales, 23 y 24.07.2020, Commissioner of Police (NSW) v Gibson, párs. 81 y 82.

${ }^{100}$ Consejo de Estado de Francia, M. A... Ligue des Droits de l'Homme Confédération Generale du Travail et autres, pár. 14 .

${ }^{101}$ Pero solo podrían. El tribunal de Madrid, por ejemplo, sostuvo para convalidar una prohibición absoluta que, no obstante la "desescalada" de las regulaciones sanitarias, no debe olvidarse "la fragilidad de este lento y delicado proceso”. Convalidó la prohibición. Tribunal Superior de Justicia de Madrid, Sentencia $\mathrm{N}^{\circ} 195 / 2020$, cons. $5^{\circ}$.

102 Consejo de Estado de Francia, M. A... Ligue des Droits de l'Homme Confédération Generale du Travail et autres, pár. 14.

103 Así ocurrió en un caso concerniente a la reunión de personas para ejercer el culto en Corte Constitucional Federal de Alemania, 29.04.2020, 1 BvQ 44/20.

${ }^{104}$ Corte Suprema de New South Wales, Commissioner of Police v Gray, pár. 66. 
respeto a las medidas, apenas empezó la protesta dejaron de satisfacer esos requerimien$\operatorname{tos}^{105}$. Y aunque ocurrió ello, en una ocasión posterior un tribunal de Berlín sostuvo que la violación de medidas sanitarias en el pasado no podía ser considerado, sin más, como una razón para prohibir protestas futuras. Al autorizar una protesta que la policía de Berlín había prohibido, señaló que la autoridad debía presentar "dudas justificadas sobre si los participantes no están dispuestos a cumplir los requisitos del Decreto de protección contra la infección por SARS-CoV-2 de conformidad con los requisitos de la prohibición de reunirse" 106 .

Segundo, porque en otras latitudes estas medidas, en caso de ser posibles, permiten ofrecer un mayor margen para la realización de reuniones en lugares de uso público y no en su contra. Esto quiere decir que las autoridades deben echar mano a la discrecionalidad de la que gozan para escrutar adecuadamente las notificaciones de realización de reuniones en lugares de uso público caso a caso y no imponiendo prohibiciones generales y absolutas. Así lo sostuvo la Corte Constitucional Federal alemana que le reprochó a la ciudad de Giessen haber actuado de manera muy tosca al no haber considerado que los organizadores de la protesta les habían propuesto el uso de detalladas medidas de seguridad $^{107}$.

El Tribunal Administrativo de Berlín vuelve a ofrecer la posición más demandante al señalarle a las autoridades que no basta con establecer protocolos de protección de la salud. Era preciso, además, que la autoridad misma "tenga que hacer también sus propias consideraciones para reducir aún más el riesgo de infección. La responsabilidad de esto no recae únicamente en el solicitante de la reunión"108. Como contrapartida, la Corte Suprema de Queensland, Australia, prohibió la realización de una protesta que buscaba desarrollarse en plena pandemia en el puente Story Bridge, sobre la base solo de consideraciones generales acerca del ejercicio del derecho de reunión. Sostuvo que no era ni siquiera necesario mirar a las consideraciones sanitarias. ${ }^{109}$

\section{Conclusiones}

De todas las medidas que se han adoptado para efectos del control de la expansión de la pandemia, las restricciones a las actividades que se desarrollan en los espacios públicos han sido las más intensas. Chile mismo va a enterar un año bajo toque de queda. De todas esas actividades, las que más intensamente se han visto afectadas son las reuniones públicas - una "cosa fina”, parafraseando a Sen-. Las apremiantes circunstancias

105 ReUters, 2020.

106 Tribunal Administrativo de Berlín, 1 L 296/20, para. II.1.a). Aunque, como se indicó antes, un tribunal de Madrid hizo exactamente lo que el tribunal alemán acá reprocha para convalidar una prohibición.

107 Corte Constitucional Federal de Alemania, 15.04.2020, 1 BvR 828/20.

108 Tribunal Administrativo de Berlín, 1 L 296/20, para. II.1.b)

${ }^{109}$ Corte Suprema de Queensland, 8.08.2020, Attorney-General for the State of Queensland v Sri E Ors, pár. 37. 
sanitarias, sin embargo, nos han hecho perder de vista otros intereses que, como los derechos y libertades fundamentales, debieran también ser considerados.

Las sentencias que acá se han repasado muestran que los tribunales de otros países han estado atentos a sumar esas consideraciones. Como se ha señalado, esto que parece obvio en tiempos regulares, en el actual contexto se ha vuelto un verdadero dilema, en especial si se anota que de acuerdo con la evidencia estas restricciones son efectivas en el control de la propagación del virus.

De la exploración inicial que se propone con el análisis de estas sentencias, hemos aprendido que las atribuciones de las autoridades, más o menos reguladas, se han sabido cotejar con los derechos que las personas han reclamado. Si bien del examen hemos podido observar que los tribunales han conferido un sitial especial a las consideraciones que las autoridades civiles y sanitarias han apuntado, esas consideraciones han sido escrutadas con el respeto adecuado (proporcional) de los derechos y libertades afectados. Así, los tribunales han señalado que las prohibiciones absolutas deben ser escrutadas con mayor intensidad -convalidándolas en algunos casos, rechazándolas en otras-. A la hora de evaluar regulaciones menos intensas, los tribunales han sabido acomodar también el respeto a los derechos, para lo que ha sido relevante el respeto a las medidas sanitarias de control de la propagación del virus que las mismas personas que recurren a la protesta han abrazado. Una "manera" novedosa de regulación a las protestas y que se explica por el contexto. En cualquier caso, ya sea en la evaluación de las prohibiciones como de las demás regulaciones, los tribunales han tenido en cuenta los antecedentes sanitarios (por ej. los relativos a una mayor o menor expansión del contagio) que las autoridades informan semana a semana.

A futuro, mientras las publicaciones referidas a las regulaciones de las protestas en pandemia ya son numerosas, este estudio debe ser complementado expandiendo la mirada a los criterios que se han utilizado para evaluar restricciones a actividades diferentes a las que acá se han revisado. Ello ofrecerá criterios que confirmen o desmientan los que acá se han deducido del estudio de las sentencias, pero que, sin duda, permitirán que, al menos desde el punto de vista del derecho, estemos algo más preparados para la próxima ocasión.

\section{BIBLIOGRAFÍA}

Altshuler, Ellery, 2020: "Coronavirus containment depends on human rights: freedom of expression and press are needed to fight pandemic", International Journal of Human Rights in Healthcare, volumen ahead-of-print.

BARENDT, Eric, 2007: Freedom of Speech, Oxford: Oxford University Press.

Bethke, Felix y WolfF, Jonas, 2020: "COVID-19 and shrinking civic spaces: patters and consequences", $Z$ Friedens und Konflforsch, $\mathrm{N}^{\circ} 9$.

Butler, Judith, 2020: Notes Toward a Performative Theory of Assembly, Cambridge: Harvard University Press.

ButLer, Judith, 2015:Sin Miedo: formas de Resistencia a la violencia de hoy, (trad.) Inga Pellisa (2a edición chilena), Santiago, Taurus. 
Chia, T. y Oyeniran, O.I., 2020: "Human health versus human rights: An emerging ethical dilemma arising from coronavirus disease pandemic", Ethics, Medicine and Public Health, $\mathrm{N}^{\circ} 14$.

Comisión Interamericana de Derechos Humanos (20 de marzo de 2020). La CiDH y su REDESCA instan a asegurar las perspectivas de protección integral de los derechos humanos y de la salud pública frente a la pandemia del COVID-19. Recuperado el 26.01.21, Comisión Interamericana de Derechos Humanos: HTTP:/WWW.OAS.ORG/ES/CIDH/PRENSA/ COMUNICADOS/2020/060.ASP

Cordero, Luis, 2020: "Delimitando la revisión judicial en la emergencia", El Mercurio Legal, 28 de mayo de 2020.

Dave, D., Friedson, A., Matsuzawa, K., Sabia, J. y Safford, S., 2021: "Black Lives Matter protests and risk avoidance: the case of civil unrest during a pandemic", National Bureau of Economic Research, Working Paper 27408. Disponible en HTTPS://PAPERS.SSRN. COM/SOL3/PAPERS.CFM?ABSTRACT_ID=3632635. [Fecha de consulta: 12.01.21].

Della Porta, Donatella, 2020: "How progressive social movements can save democracy in pandemic times", Interface, volume 12, $\mathrm{N}^{\circ} 1$.

Douglas, Delia, 2020: "Very Necessary: Pandemic Protests and Pedagogies of Possibility", en Andrea Rounce y Karine Levasseur (editoras), COVID-19 in Manitoba. Public policy responses to the First Wave, Winnipeg, University of Manitoba Press, pp. 206-212.

Gargarella, Roberto, 2020: "Necesitamos resguardar los derechos fundamentales", Clarín, 28 de mayo de 2020.

Gerbaudo, Paolo, 2020: "The pandemic crowd", Journal of International Affairs, volume 73, No 2.

Gibson, A., Chancellor, R., Cooke, N., Park Dahlen, S., Patin, B. y Shorish, Y., 2020: "Struggling to breathe: COVID-19, protest and the LIS response", Equality, Diversity and Inclusion, volumen ahead-of-print. Disponible en HTTPS://WWW.EMERALD.COM/INSIGHT/CONTENT/DOI/10.1108/EDI-07-2020-0178/FULL/HTML. [Fecha de consulta: 26.08.2020].

Di Giminiani, P., Pérez, M. y Quezada, C., 2020: "Nueva normalidad, vieja precariedad: la crisis pandémica en Santiago de Chile”, City E Society, volumen 32, No 2.

Guinier, Lani y Torres, Gerald, 2014: "Changing the Wind: Notes Toward a Demosprudence of Law and Social Movements", Yale Law Journal, volumen 123, $\mathrm{N}^{\circ} 8$.

Harper, C., Satchell, L., Fido, D. y Latzman, R., 2020: "Functional Fear Predicts Public Health Compliance in the COVID-19 Pandemic", International Journal of Mental Health and Addiction, pp. 1-14. Disponible en HTTPS://WWW.NCBI.NLM.NIH.GOV/PMC/ ARTICLES/PMC7185265/. [Fecha de consulta: 1 de septiembre de 2020].

Honey-Rosés, J., Anguelovski, I., Chireh, V., Daher, C., Konijnendijk van den Bosch, C., LITT, J., 2020: "The impact of COVID-19 on public space: an early review of the emerging questions - design, perceptions and inequities”, Cities $\mathcal{E}$ Health, No especial: COVID-19.

Instituto Nacional de Derechos Humanos de Chile - ACNUDH, 2014: Protesta Social y Derechos Humanos: Estándares Internacionales y Nacionales, Santiago, INDH-ACNUDH.

IsmangIL, Milan y Lee, Maggy, 2020: "Protests in Hong Kong during the Covid-19 pandemic", Crime Media Culture, July 2020: Covid-19 Symposium.

JaCKson, Vicki, 2012: “Comparative Constitutional Law: Methodologies”, en Michel Rosenfeld y András Sajó (editors), The Oxford Handbook of Comparative Constitutional Law, Oxford, Oxford University Press, pp. 54-74.

JHA, Ashish, 2020: "Why protests aren't as dangerous for spreading coronavirus as you might think", The Guardian, 18 de junio de 2020.

Joseph, Sarah, 2020: "International Human Rights Law and the Response to the COVID-19 Pandemic", Journal of International Humanitarian Legal Studies, $\mathrm{N}^{\circ} 11$. 
Kampmark, Binoy, 2020: "Protesting in Pandemic Times. Covid-19, Public Health, and Black Lives Matter", Contention, volume 8, № 2 .

Kowalewski, Maciej, 2020: "Street protests in times of COVID-19: adjusting tactics and marching 'as usual'”, Social Movements Studies, pp. 1-8. Disponible en HTTPS://WWW. TANDFONLINE.COM/DOI/FULL/10.1080/14742837.2020.1843014. [Fecha de consulta: 15 de noviembre de 2020].

KwoK, Kyle, 2021: "Narrativizing the Face Mask as the Design of Dissent at the Intersection of Protest and Pandemic", Design and Culture, pp. 1-14. Disponible en HTTPS://WWW. TANDFONLINE.COM/DOI/FULL/10.1080/17547075.2021.1872008. [Fecha de consulta: 26 de enero 2021].

Landon, William J., 2013: Lorenzo di Filippo Strozzi and Niccolò Machiavelli Patron, Client, and the Pistola fatta per la peste / An Epistle Written Concerning the Plague, Toronto, Buffalo y Londres: University of Toronto Press.

Lovera, Domingo, 2010: "El mito de la libertad de expresión en la creación artística". Revista de Derecho (Valdivia), No 23.

Lovera, Domingo, 2015: "Libertad de expresión, derecho de reunión y protesta en la Constitución”, en Jaime Bassa et al. (editores), La Constitución Chilena. Una revisión crítica a su práctica política, Santiago, Lom, pp. 99-119.

Lovera, Domingo, 2020: "Derecho de reunión”, en Pablo Contreras y Constanza Salgado (editores), Curso de Derechos Fundamentales, Valencia, Tirant lo Blanch, pp. 507-542.

Lovera, Domingo, 2021: "Human rights, poverty and mobilizations", en Martha Davis, Morten Kjaerum, y Amanda Lyons (editores), Research Handbook on Human Rights and Poverty, Cheltenham - Northampton, Edward Elgar, pp. 339-354.

Mateos, Arnulfo, 2021: "El reglamento del coronavirus y la protesta pública en la ciudad de Stuttgart", Universitas, $\mathrm{N}^{\circ} 34$.

Mendes, Luís, 2020: "How can we quarantine without a home? Responses of activism and urban social movements in times of COVID-19 pandemic crisis in Lisbon", Tijdschrift voor Economische en Sociale Geografie, volumen 111, No 3 .

Mitchell, Don, 2013: "The Liberalization of Free Speech: Or, How Protest in Public Space in Silenced”, en Walter Nicholss et al. (editores), Spaces of Contention. Spatialities and Social Movements, Londres y Nueva York, Routledge, pp. 47-68.

Neyman, Gregory y Dalsey, William, 2020: "Black Lives Matter protests and COVID-19 cases: relationship in two databases", Journal Public Health (Oxford), Advance online publication. Disponible en HTTPS://DOI.ORG/10.1093/PUBMED/FDAA212. [Fecha de consulta: 2.02.21].

Parry, L., Asenbaum, H. y Ercan, S., 2020: "Democracy in flux: a systemic view on the impact of COVID-19", Transforming Government: People, Process and Policy, volumen ahead-of-print, $\mathrm{N}^{\circ}$ ahead-of-print. Disponible en HTTPS://DOI.ORG/10.1108/TG-09-2020-0269. [Fecha de consulta: 23.01.21].

Pleyers, Geoffrey, 2020: "The Pandemic is a battlefield. Social movements in the COVID- 19 lockdown", Journal of Civil Society. Disponible en HTTPS://DOI.ORG/10.1080/1744868 9.2020.1794398. [Fecha de consulta: 26.08.20].

Post, Robert C., 2012: Democracy, Expertise, and Academic Freedom: A First Amendment Jurisprudence for the Modern State, New Haven y Londres: Yale University Press.

Pozen, David y Scheppele, Kim, 2020: "Executive Underreach, in Pandemics and Otherwise", American Journal of International Law, volume 114, $\mathrm{N}^{\circ} 4$.

Preuss, Ulrich, 2012: "Associative Rights (The Rights to the Freedoms of Petition, Assembly, and Association)”, en Michel Rosenfeld y András Sajó (editores), The Oxford Handbook of Comparative Constitutional Law, Oxford, Oxford University Press, pp. 946-965. 
Priel, Dan, 2020: "COVID-19: Cost-Benefit Analysis and Politics”, Osgoode Hall Law Jorunal, volumen $3, \mathrm{~N}^{\circ} 57$.

Reicher, Stephen y StotT, Clifford, 2020: "On order and disorder during the COVID-19 pandemic", British Journal of Social Psychology, volumen 59, $\mathrm{N}^{\circ} 3$.

REUTERs (26 de agosto de 2020). Berlin bans protest against coronavirus curbs, Recuperado el 27.08.2020, de Reuters: HTTPS://AR.REUTERS.COM/ARTICLE/IDUSL8N2FS36F.

ReYes, Carlos (28 de mayo de 2020). Mañalich reconoce que en un sector de Santiago 'hay un nivel de pobreza y hacinamiento del cual yo no tenía conciencia de la magnitud que tenía'. Recuperado el 1.09.20, de La Tercera: HTTPS://WWW.LATERCERA.COM/POLITICA/NOTICIA/ MANALICH-RECONOCE-QUE-EN-UN-SECTOR-DE-SANTIAGO-HAY-UN-NIVELDE-POBREZA-Y-HACINAMIENTO-DEL-CUAL-YO-NO-TENIA-CONCIENCIA-DELA-MAGNITUD-QUE-TENIA/5BQZLGLOPVDDPKQ2SNSSSWRGYU/

SALÁt, Orsolya, 2015: The Right to Freedom of Assembly, Oxford - Portland: Hart Publishing.

Scheppele, Kim, 2008: "Legal and Extra-Legal Emergencies", en Keith Whittington, Daniel Kelemen y Gregory Caldera (editors), The Oxford Handbook of Law and Politics, Oxford Nueva York, Oxford University Press, pp. 165-184.

Schwabe, Jürgen, 2003: Cincuenta Años de Jurisprudencia del Tribunal Constitucional Federal Alemán, Montevideo: Konrad Adenauer Stiftung - Ediciones Jurídicas Gustavo Ibáñez.

Schmitr, Carl, 2008, Constitutional Theory, (trad.) Jeffrey Seitzer, Durham y Londres: Duke University Press.

SchweIngruber, David, 2000: "Mob Sociology and Escalated Force: Sociology's Contribution to Repressive Police Tactics", The Sociological Quarterly, volumen 41, No 3 .

SEN, Amartya, 2000: Desarrollo y Libertad, (trad.) Esther Rabasco y Luis Toharia, Buenos Aires, Planeta.

SEN, Amartya, 2013: "Press freedom: what is good for?", Index on Censorship, volumen 42, $\mathrm{N}^{\circ} 3$.

SPADARO, Alessandra, 2020: “COVID-19: Testing the Limits of Human Rights”, European Journal of Risk Regulation, volumen $11 \mathrm{~N}^{\circ} 2$.

Tello, Monique (1 de Julio de 2020). Protesting in the time of COVID-19. Recuperado el 22.08.2020, de The Harvard Health Blog: HTTPS://WWW.HEALTH.HARVARD.EDU/BLOG/ PROTESTING-IN-THE-TIME-OF-COVID-19-2020070120541.

TognotTi, Eugenia, 2013: "Lessons form the History of Quarantine, from Plague to Influenza A", Emerging Infectious Diseases, volumen 18, No 2 .

Tushnet, Mark, 2008: Weak Courts, Strong Rights. Judicial review and social welfare rights in comparative constitutional law, Princeton - Oxford: Princeton University Press.

United Nations - Office of the High Commissioner of Human Rights (16 de marzo de 2020). COVID-19: States should not abuse emergency measures to suppress buman rights - UN experts. Recuperado el 26.08.20, Office of the High Commissioner of Human Rights: HTTPS:/WWW. OHCHR.ORG/EN/NEWSEVENTS/PAGES/DISPLAYNEWS.ASPX?NEWSID = 25722

UrbinAti, Nadia, 2011: "Representative democracy and its critics", en Sonia Alonso, John Keane y Wolfgang Merkel (editores), The Future of Representative Democracy, Cambridge y Nueva York, Cambridge University Press, pp. 23-49.

Urbinati, Nadia, 2014: Democracy Disfigured. Opinion, truth, and the people, Cambridge y Londres: Harvard University Press.

Velasco, Francisco, 2020: "Libertades públicas durante el estado de alarma por la COVID-19”, en David Blanquer (coordinador), COVID-19 y Derecho Público (durante el estado de alarma y más allá), Valencia, Tirant lo Blanch, pp. 79-133.

Wiley, Lindsay y Vladeck, Stephen, 2020: "Coronavirus, civil liberties, and the courts: the case against 'suspending' judicial review”, Harvard Law Review forum, volumen 133, No 9. 
Sentencias judiciales nacionales

Corte Suprema, sentencia de 4 de noviembre de 2014, rol 23.540-2014.

Corte Suprema, sentencia de fecha 3 de agosto de 2020, rol 62897-2020.

\section{Sentencias judiciales extranjeras}

Corte Suprema de Canadá, sentencia de 24 de enero de 2002, R.W.D.S.U., Local 558 v. PepsiCola Canada Beverages (West) Ltd. [2002] 1 SCR 156.

CoRTE Constitucional de Sudáfrica, sentencia de 17 de agosto de 2006, Doctors for Life International $v$ Speaker of the National Assembly and Others (CCT12/05) [2006] ZACC 11.

CorTe EDH, sentencia de 7 de febrero de 2017, Case of Lashmankin and others v. Russia, Applications nos. 57818/09.

Conte Superior de Merrimack, sentencia de 25 de marzo de 2020, Binford et al. v. Governor Sununu, No. 217-2020-CV-00152.

Corte Constitucional de Colombia, sentencia de 7 de marzo de 2018, sentencia C-009/18.

Corte Constitucional de Colombia, sentencia de 7 de marzo de 2018, Sentencia C-009/18.

Corte Constitucional Federal de Alemania, sentencia de 15 de abril de 2020, 1 BvR 828/20.

Corte Federal Constitucional de Alemania, sentencia de 17 de abril de 2020, 1 BvQ 37/20.

Corte Constitucional Federal de Alemania, sentencia de 29 de abril de 2020, 1 BvQ 44/20.

Tribunal Superior de Justicia de Madrid, sentencia de 30 de abril de 2020, Sentencia N ${ }^{\circ}$ 195/2020.

Tribunal Superior de Justicia de Zaragoza, sentencia de 30 de abril de 2020, Sentencia No 151/2020.

Corte del Distrito Este de California de los Estados Unidos de Norteamérica, sentencia de 8 de mayo de 2020, Givens et al. v. Newsom et al., No. 2-20-cv-00852-JAM-CKD.

Corte Suprema de los Estados Unidos, sentencia de 29 de mayo de 2020, South Bay United Pentecostal Church, et al. v. Gavin Newsom, Governor of California et al., 590 U.S. (2020)

Corte Suprema de New South Wales, sentencia del 23 y 24 de julio de 2020, Commissioner of Police (NSW) v Gibson [2020] NSWSC 953.

Consejo de Estado de Francia, sentencia de 26 de julio de 2020, Confédération Generale du Travail et autres Association SOS Racisme, Nos 441257, 441263, 441384.

Corte Constitucional de Sudáfrica, sentencia de 19 de noviembre de 2018, Mlungwana and Others $v S$ and Another [2018] ZACC 45 [61].

Consejo de Estado de Francia, sentencia de 13 de junio de 2020, M. A... Ligue des Droits de l'Homme Confédération Generale du Travail et autres, Nos 440846, 440856, 441015.

Tribunal Constitucional de Perú, sentencia de 3 de julio de 2020, expediente 00009-2018-PI/TC.

Conte Suprema de New South Wales, sentencia de 3 de julio de 2020, Commissioner of Police $v$ Gray $[2020]$ NSWSC 867.

Corte Suprema de los Estados Unidos, sentencia de 24 de julio de 2020, Calvary Chapel Dayton Valley v. Steve Sisolak, Governor of Nevada, et al., 591 U.S.

Corte Suprema de Queensland, sentencia de 8 de agosto de 2020, Attorney-General for the State of Queensland v Sri E Ors, [2020] QSC 246.

Tribunal Administrativo de Berlín, sentencia de 28 de agosto de 2020, 1 L 296/20.

Corte Suprema de los Estados Unidos, sentencia de 25 de noviembre de 2020, Roman Catholic Diocese of Brooklyn, New York v. Andrew M. Cuomo, 592 U.S. (2020). 
